\title{
Market pricing of credit-linked notes: the case of retail structured products in Germany
}

\section{Andreas Rathgeber}

Department for Human and Economic Sciences, UMIT - University for Health and Life Sciences, Eduard Wallnöfer-Zentrum 1, 6060 Hall/Tyrol, Austria;

email: andreas.rathgeber@umit.at

\section{Yun Wang}

Universität Augsburg, Lehrstuhl für Finanz- und Bankwirtschaft, Universitätsstrasse 16, 86159 Augsburg, Germany;

email: yun.wang@student.uni-augsburg.de

\begin{abstract}
The volume of the primary market of certificates for retail investors has increased enormously in the past ten years, and German banks have recently started issuing credit-linked notes (CLNS). As with other types of certificates, the question can be raised as to whether coupon payments for these instruments are fair and adequate compared with the related risk and, if not, what the reasons for this mispricing are. In this paper we analyze the pricing of 136 outstanding CLNs and discover that CLNs are generally greatly overpriced in the primary market. Furthermore, we find strong evidence for an essential hypothesis that is still debated in the literature: the more complex the product and the less transparent the market, the more overpricing there tends to be.
\end{abstract}

\section{INTRODUCTION}

The volume of the primary market of certificates for retail investors has increased enormously in the past ten years. Beginning with simple cash or share bonds, banks have issued increasingly complex products over that time period. Recently, German banks have started to issue credit-linked certificates, called credit linked notes (CLNs), which allow them to securitize their credit risk, especially concentration risk. The mechanism of a CLN is as follows. The buyer of a CLN only receives the payments for the notes if the reference entity (which is some other debtor) does not go into default. Investors therefore have the option to invest in the credit risk of debtors, which they normally cannot. At this point, investors can buy the credit risks of several large reference entities with a basket-credit-linked note. In contrast with simple CLNs, the buyer of a basket-credit-linked note only receives payments if all the reference 
entities (first-to-default model) do not go into default. In this way, the higher risk is only taken by the buyer in case an attractive coupon payment is linked to notes. Hence, in a similar way to other types of certificates, the question can be raised as to whether the coupon payments for, and the issue prices of, these instruments are fair and adequate compared with the related risk and, if not, what the reasons for this mispricing are.

There are several studies on equity-linked notes, or certificates, especially on the European markets. The first studies by Chen et al (1990) and Chen and Sears (1990) concentrate on finding significant differences between quoted prices and theoretically fair values of products in the US market, while more recent studies by, for example, Burth et al (2001), Brown and Davis (2004), Wilkens et al (2003) and Gruenbichler and Wohlwend (2005) ascertain the overpricing in several non-US primary markets for reverse convertibles, discount certificates or endowment warrants. Consequently, subsequent studies have concentrated on discovering the causes of overpricing. Overpricing seems to be positively related to the replicability and the complexity of the product, among other causes (see, for example, Benet et al (2006) and Entrop et al (2009)). This theory is supported by several studies (see Hernández et al (2007a) and Stoimenov and Wilkens (2005)). Furthermore, Wallmeier and Diethelm (2009) show that high coupons stimulate the interests of retail investors and are linked to a large overpricing of these certificates.

There is no comparable study of overpricing. The results of such a study would be of special interest because they would shed some light on the reasons for overpricing. These products are similar to bonds and reverse convertibles, and they make retail investors believe that they are straight bonds. Furthermore, the replicability for private investors, in contrast with institutional investors, is not practicable and the complexity of the valuation procedure only results in a monotone ascending function of the size of the basket of reference entities. We can therefore measure the complexity by means of an ordered scale since complexity strictly increases with the number of reference entities and payment days. Hence, our research question can be established as follows: are coupon payments for, and issue prices of, the CLN fair and adequate compared with the related risk, and if not, what are the reasons for the mispricing?

To answer this question we first identify all major CLN issuers in the German market and gather the issue prospectuses of their 136 outstanding CLN products. After collecting the data, a valuation model is developed to determine theoretically fair values by means of market prices only. Our approach aims to calculate the differences between fair values and prices offered. We are also able to empirically verify several hypotheses that we formulate for the German CLN market.

First, we introduce the underlying theory of credit derivatives (with particular focus on CLNs) and formulate our hypotheses. We then explain the details of our valuation 
FIGURE 1 The concept of CLNs.

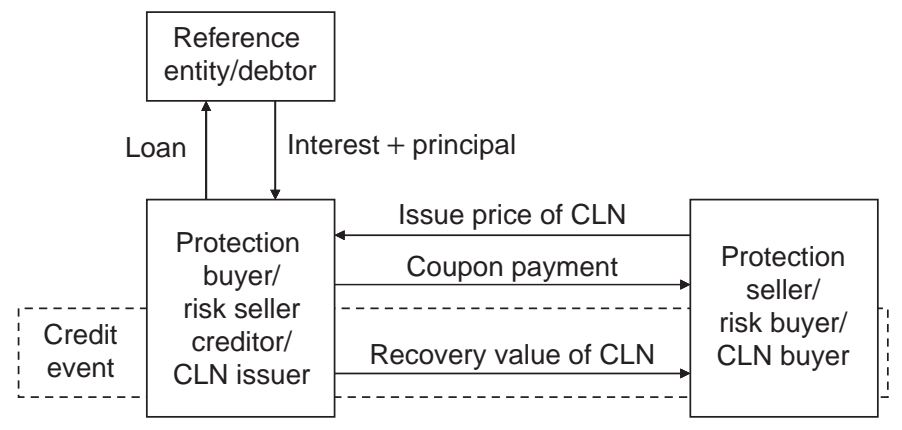

framework and describe the data sources used during the valuation process. After preparing both the model and the data, we present the results of CLN valuation and test which of the hypotheses that we formulated before the valuation are statistically valid. Finally, the knowledge gained by our empirical analysis is summarized and some suggestions concerning the improvement and extension of our work are provided.

\section{PRODUCTS AND HYPOTHESES}

\subsection{CLNs for the retail investor}

A CLN is a credit derivative that represents a bilateral contract under which the seller sells the credit risk of the reference entity and receives a certain premium from the protection buyer (Fabozzi et al (2007, p. 67)). The payment structure of a CLN is linked to the credit standing of one or more underlying reference assets (see Figure 1). In the case of a credit event, the coupon payment will be suspended and the investors will receive a recovery rate in the form of either a cash settlement or physical delivery of the underlying assets. Since the payments are funded with the help of securitization techniques, the protection buyer (ie, the issuer of the notes) does not take the credit risk of the seller (ie, the investor) if a credit event arises. This enables the participation of a larger group of players, including retail investors who are willing to bear that risk in return for a higher yield. Consequently, investors also bear the credit risk of the corresponding CLN issuer.

Depending on the form of the embedded credit derivatives, CLNs can be further divided into several categories, each of which has a more specific name (see Telpner (2004, p. 10)). The scope of our work covers credit default notes and basket credit 
default notes, which represent the vast majority of the CLN variants in the German retail market. We continue to use the generic term CLN since it is more widely known.

\subsection{Hypotheses}

The fact that the protection buyer of other credit derivative products must bear the risk of a possible default on the part of the protection seller makes it very difficult to offer most types of credit derivatives publicly in the retail market. Therefore, CLNs are the only major credit derivative products available to retail investors and they have been marketed worldwide as low-risk structured products. In Hong Kong and Singapore, for example, CLNs have been labeled with the product name "mini-bond" (for details on the CLN market for investors, see Fabozzi et al (2007, p. 77)). However, for individual investors, the CLN construct is not easy to replicate because there exists no adequate position in the retail market. Even if martingale probabilities for single entities were available, basket products would be difficult to price. A potential information asymmetry in the credit market could motivate CLN issuers to overprice their products at their issuance. Therefore, our major hypothesis is as follows.

Hypothesis 1: CLNs in the German retail market are generally overpriced.

In addition to the major hypothesis of overpricing, we also formulate several other hypotheses regarding possible factors that could influence the significance of overpricing. Since the CLN contracts analyzed are all based on the principle of first-todefault, we believe that the increased risk of CLNs with large numbers of underlying reference entities cannot be fully compensated by their insignificantly higher coupon rates when compared with single referenced products. Furthermore, calculating a fair price for multiple referenced CLNs requires a level of expertise and computational facilities that most retail investors do not have. In accordance with the idea of equitylinked notes (see, for example, Hernández et al (2007b)) this lack of transparency might encourage CLN issuers to overprice their products with multiple underlying references even more than those with fewer entities or a single reference.

Hypothesis 2: the more underlying reference entities there are, the more significant the overpricing will be.

The third hypothesis concerns the "first-sight effect" of coupon payments, which are comparable to equity-linked bonds (Wallmeier and Diethelm (2009, p. 12)). There are usually hidden factors behind high coupon rates, such as an extremely risky underlying or a generally high interest level in the market that the investor does not realize. This could be especially confusing for CLNs with mixed coupon structures, which usually include fixed high-rate payments at the beginning followed by float-rate payments. Therefore, the size and type of coupon payments could also affect the significance of overpricing. 
Hypothesis 3: the higher the coupon rate, the more significant the overpricing.

Credit-linked notes with longer maturities incorporate a greater risk, which will change the creditworthiness of the underlying reference entities. Since a longer maturity usually indicates more payment days, the number of payment days will be used as an additional control variable during the test. Moreover, we have discovered during the valuation process that the complexity of the calculation strictly increases with the number of payment days. According to our model, it could take days to determine a fair price for a complex CLN product with a long maturity that also includes a lot of payment days, especially if it has a large number of underlying references (see Stoimenov and Wilkens (2005, p. 2980)). Employing the complexity argument again, we can formulate the fourth hypothesis in a similar way to the second hypothesis.

Hypothesis 4: the longer the maturity, the more significant the overpricing will be.

We also want to discover whether overpricing has decreased in accordance with the development of the CLN market (see Szymanowska et al (2009, p. 913)).

Hypothesis 5: the earlier the date of issue, the more significant the overpricing.

According to Szymanowska et al (2009, p. 917), the market power and marketing strategy of the issuer might also have a significant influence. We want to discover whether this is true using our final hypothesis.

Hypothesis 6: the more products an issuer offers, the more significant the overpricing will be.

\section{METHODOLOGY}

\subsection{Choice of model}

Although there is still no industrial standard valuation model that applies to all credit derivatives, two basic theoretical approaches are usually applied to modeling the credit risks (Bielecki and Rutkowski (2002, p. 26)). On the one hand we have the structured model, which was developed by Merton (1974). In compliance with Hui and Lo (2002), the value of a firm is modeled as a continuous diffusion process, and a default occurs if the firm value falls below a lower bound, which can be interpreted as the liability of the firm. The stock price is normally used to calibrate the valuation model, since stocks can be seen as options on firm value. On the other hand there is the reduced-form model (Jarrow and Turnbull (1997) and Duffie and Singleton (1999)), which is characterized by assumptions regarding the intensity rate, the risk-free rate, the correlation and the recovery rate. The default is modeled as a stochastic event depending on the intensity rate of the underlying process, under 
which macroeconomic factors and firm-specific data can be integrated. The value of related credit derivatives can be modeled as expectations depending on the realization of the stochastic process involved. The calibration of the process is based on the prices of defaultable instruments, such as bonds, which are used to build a complete interest and credit-spread structure from which the probability of default can be derived.

When choosing the applied credit risk model, we faced a trade-off between using a sophisticated model with historical parameter estimation (and therefore huge parameter uncertainty) and using a simplified approach with much less input and marketbased parameter estimation. Considering the advantages of the existing credit risk models and the data available, we decided to use the reduced-form-model approach. Our approach can be understood as a multiborrower Jarrow and Turnbull model for which the default probabilities are calculated on the basis of credit default swap (CDS) spreads. These probabilities are then used to calculate the net present value of a CLN contract. In addition, we incorporate the asset correlation of the underlying assets so that the model is flexible enough to model multiple defaults of the reference entities. This is important for the valuation of CLNs with multiple references. The details of our approach are explained in the following sections.

\subsection{Valuation of CLNs with a single reference entity}

\subsubsection{CDS spreads and implied probability of default}

Since a CLN can be interpreted as a bond with embedded CDSs, it is necessary to derive the default probabilities from the CDS spreads of reference entities. These implied default probabilities include the risk premium and, therefore, do not represent real probabilities. According to Merrick (2001), they are risk-neutral probabilities in the option pricing methodology. According to the standard North American corporate CDS contract specification of the International Swaps and Derivatives Association (2003), the annual CDS premium is paid quarterly, on March 20, June 20, September 20 and December 20 of each year. Let the date of issue be $t_{0}$ for a CDS contract with maturity of $n$ years. Then the dates of premium payments are $T_{n}=\left\{t_{0.25}, t_{0.5}, t_{0.75}, t_{1}, \ldots, t_{n}\right\}$. On each of these dates, one-quarter of the annual CDS spread $\left(0.25 \mathrm{CDS}_{n}\right)$ will be paid. On the other hand, according to the standard North American corporate CDS converter specification of the International Swaps and Derivatives Association (2009), the recovery rate of a senior CDS is $40 \%$, which implies $\mathrm{REC}_{\mathrm{CDS}}=0.4$.

As the data set is limited to annual CDS contracts, we have to impose assumptions to calculate implied default probabilities for all possible maturities. To simplify the case in hand, we assume that the recovery rate will also be paid on the next possible CDS premium payment date in case of a default. This means that any credit event occurring during a quarter of a year has to be settled accordingly at the end of the 
FIGURE 2 Cashflow of a one-year CDS.

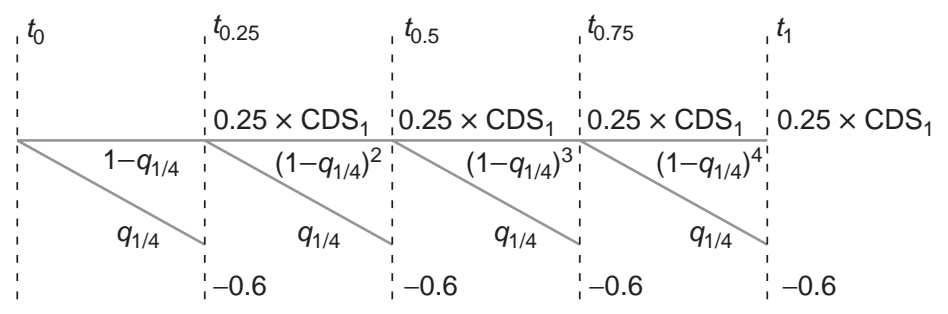

FIGURE 3 Cashflow of an $n$-year CDS in the $n$th year.

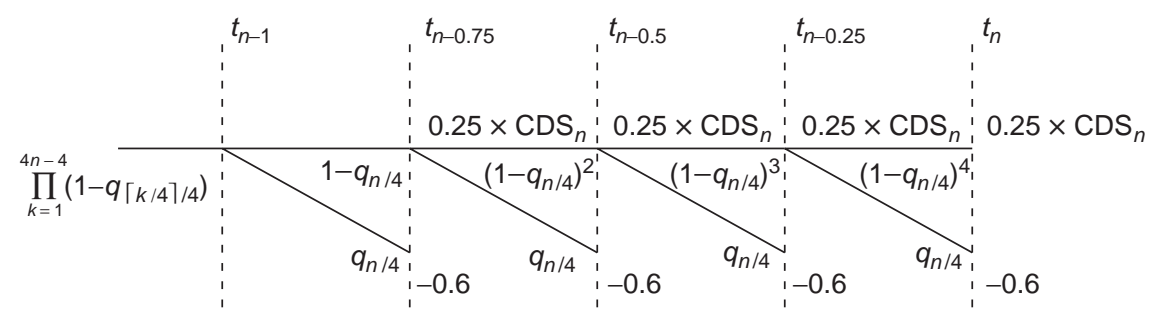

respective quarter. Furthermore, the probability of default $q$ is assumed for each CDS contract to be the same in each quarter of the year. This assumption guarantees that we are able to calculate four probabilities while having only one CDS spread. As an alternative, we use a continuous-time default model and estimate the annual default intensity, which leads to no elementary change in results.

On the basis of these two assumptions, we can now discount the expected cashflows $\mathrm{CF}_{1,1}$ (see Figure 2), which should sum to zero so that no arbitrage is possible. We start with the one-year CDS from the risk buyer's point of view. The CDS spread is set $^{1}$ in such a way that the swap is priced fairly (see Hull and White (2003)):

$$
\begin{aligned}
& \mathrm{CF}_{1,1}\left(1+r_{0.25}\right)^{-0.25}+\mathrm{CF}_{1,1}\left(1-q_{1 / 4}\right)\left(1+r_{0.5}\right)^{-0.5} \\
& +\mathrm{CF}_{1,1}\left(1-q_{1 / 4}\right)^{2}\left(1+r_{0.75}\right)^{-0.75}+\mathrm{CF}_{1,1}\left(1-q_{1 / 4}\right)^{3}\left(1+r_{1}\right)^{-1}=0 \\
& \text { where } \mathrm{CF}_{1,1}=-0.6 q_{1 / 4}+0.25 \operatorname{CDS}_{1}\left(1-q_{1 / 4}\right)
\end{aligned}
$$

\footnotetext{
${ }^{1}$ It can be proven that is always a unique solution to this system of equations.
} 
With the spot rate $r_{t}$ yield curve and CDS spreads $\mathrm{CDS}_{1}$ prepared previously, the quarterly probability of default for a one-year CDS $q_{1 / 4}$ can be solved using this equation. As a result we obtain the cumulative probability of default for the end of the first year:

$$
q_{1}=1-\left(1-q_{1 / 4}\right)^{4} \quad \text { and } \quad q_{1 / 4}=1-\sqrt[4]{1-q_{1}}
$$

Since CDS contracts with different maturities share the same underlying reference entity, they should also share the same cumulated probability of default during the same period of time. Therefore, the cumulated default probability $q_{n-1}$ for the first year can be adopted while calculating the quarterly probability of default $q_{n-1 / 4}$ for a CDS with maturity of $n$ years (see Figure 3 on the preceding page). Following this procedure, we can calculate the quarterly probability of default for a CDS with maturities of $n$ years as long as CDS spreads $\mathrm{CDS}_{n}$ are available:

$$
\begin{aligned}
\sum_{t=1}^{4 n-4} \mathrm{CF}_{n, t} \prod_{k=1}^{t-1}(1 & \left.-q_{\lceil k / 4\rceil / 4}\right)\left(1+r_{t / 4}\right)^{-t / 4} \\
& +\sum_{t=4 n-3}^{4 n} \mathrm{CF}_{n, t} \prod_{k=1}^{t-1}\left(1-q_{\lceil k / 4\rceil / 4}\right)\left(1+r_{t / 4}\right)^{-t / 4}=0
\end{aligned}
$$

where $\mathrm{CF}_{n, t}=-0.6 q_{\lceil t / 4\rceil / 4}+0.25 \mathrm{CDS}_{n}\left(1-q_{\lceil t / 4\rceil / 4}\right)$ is the cashflow of the CDS with a maturity of $n$ years at the payment date $t$ and $\lceil\cdot\rceil$ represents the ceiling function by Gauss. Since the first sum in Equation (3.3) has already been calculated by the previous $n-1$ applications of formula (3.3), the implied default probabilities $q_{n / 4}$ can be solved by means of this above-mentioned equation. The cumulative probability of default is defined recursively as:

$$
q_{n}=\left(1-\left(1-q_{n / 4}\right)^{4}\right)\left(1-q_{n-1}\right)
$$

In our case we get a cumulative probability of default $q_{1}, q_{2}, \ldots, q_{n}$ for the end of each year. Furthermore, it can be said that $q_{0}=0$, since default at the date of issue $t_{0}$ is considered to be impossible. The last step is to estimate a continuous curve of cumulated default probabilities by means of eleven data points, which consist of ten implied probabilities at ten different times of maturity, and the origin, which we have already calculated. The smoothing method that we apply is natural cubic spline interpolation (Press et al (2007, pp. 120-124)). This results in a continuous isotonic function of the cumulative probability of default defined as $Q(t)=s\left(q_{1}, q_{2}, \ldots q_{n}\right)$, as depicted in Figure 4 on the facing page.

\subsubsection{Valuation of a CLN with a fixed coupon rate}

Our first goal is to price a CLN with an annual or semiannual fixed coupon rate $C_{\mathrm{f}}$ maturing at $T_{n}$ at a face value of $N$. The issue price is $V_{i}$. Let the date of issue be $T_{0}$ 
FIGURE 4 Spline of implied default probabilities from CDS spreads.

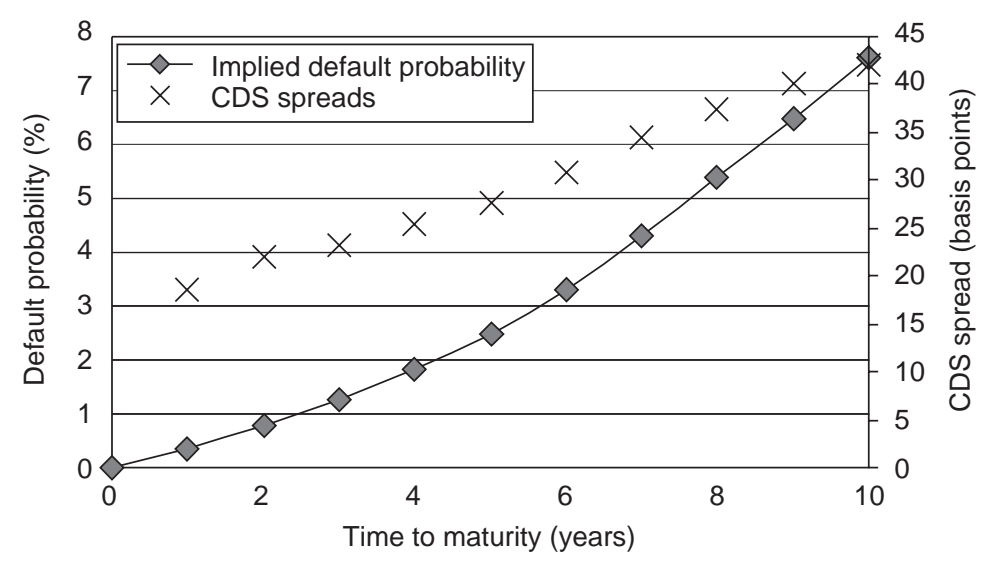

Daimler CDS spreads on October 24, 2007 and estimated cubic spline with nine equidistant inner break points and forty polynomial coefficients.

FIGURE 5 Cashflow of a CLN with fixed coupon payments.

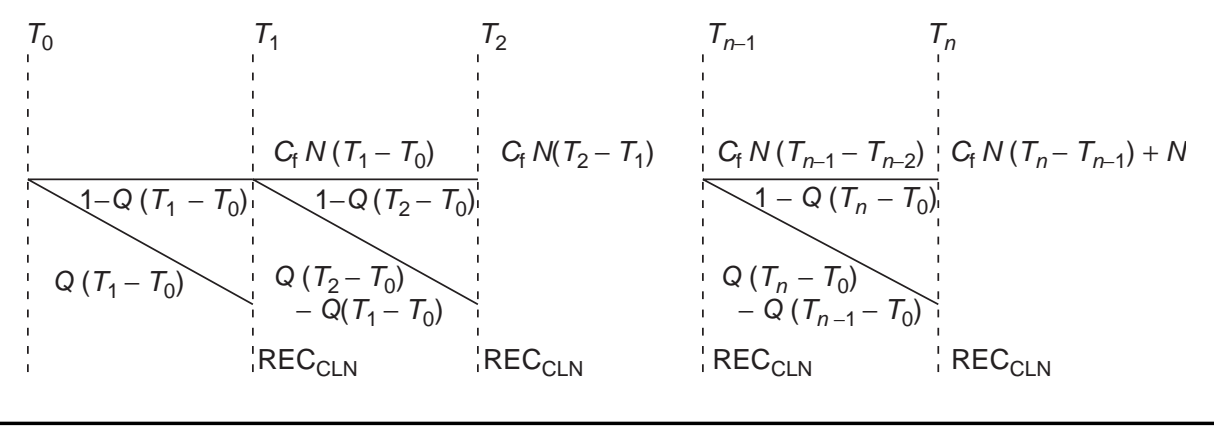

and the following payment dates be $T_{1}, T_{2}, \ldots, T_{n}$. On the basis of the default probabilities curve $Q(t)$ we can estimate the cumulated probability of default $Q\left(T_{1}-T_{0}\right)$, $Q\left(T_{2}-T_{0}\right), \ldots, Q\left(T_{n}-T_{0}\right)$ accordingly on each of these days. The expected cashflows for a CLN with a fixed annual coupon rate $C_{\mathrm{f}}$ can be replicated, as shown in Figure 5.

One major reason why CLN pricing could be difficult is that this kind of product hardly ever defaults because the reference entities are usually giant corporations or sovereigns with excellent creditworthiness. Therefore, it is hard to predict the recovery rate in such a scenario. Due to the global financial crisis, we were able to observe the 
empirical recovery rate for the first time. After Lehman Brothers declared bankruptcy on September 15, 2008, the six affected CLNs of DZ Bank quoted at around 10\% of their face value. The only Lehman-referenced CLN of the Commerzbank even quoted at $2 \%$. $^{2}$ Four weeks later, retail investors found the realized recovery rate for one of these CLNs to be $8.8 \%$. Furthermore, the product specification of the Commerzbank defined a cash settlement of $1 \%$ of the nominal value as an alternative to the delivery of the cheapest bond in case of a default. Taking all of this information into account, we first assume the recovery rate of the CLNs to be $8.8 \%$, which implies $\mathrm{REC}_{\mathrm{CLN}}=0.088$. As a second assumption, we choose the recovery rate provided by both rating agencies and the literature to be $\mathrm{REC}_{\mathrm{CLN}}=0.35$. In this case the rate is a conservatively high value because the payment is not directly comparable with the recovery rate, since the first one is fixed directly after the credit event. Therefore, according to the prospectuses, the recovery rate is derived either from bonds quoted or from the average quote of three other banks for a hypothetical claim, which is downward-biased.

If we impose the further assumption that the issuer is nearly risk-free, we can simply discount the expected cashflows back to the date of issue to determine the sum of the present values, which is also the fair price of such an instrument:

$$
\begin{aligned}
V_{\mathrm{f}}=\sum_{t=1}^{n}( & \left(C_{\mathrm{f}} N\left(T_{t}-T_{t-1}\right)+1^{\mu} N\right)\left(1-Q\left(T_{t}-T_{0}\right)\right) \\
& \left.\quad+\operatorname{REC}_{\mathrm{CLN}} N\left(Q\left(T_{t}-T_{0}\right)-Q\left(T_{t-1}-T_{0}\right)\right)\right)\left(1+r_{T_{t}-T_{0}}\right)^{T_{0}-T_{t}}
\end{aligned}
$$

where $\mu=\lfloor t / n\rfloor$ is the result of the floor function.

To calculate the overpricing we evaluate the difference between the theoretically fair price $V_{\mathrm{f}}$ and the real issue price. $\Delta V=V_{\mathrm{i}}-V_{\mathrm{f}}$. A positive $\Delta V$ indicates overpricing and vice versa.

Furthermore, we can assume the issue price to be fair and estimate the implied recovery rate, which satisfies this assumption:

$$
\mathrm{REC}_{\mathrm{imp}}=\frac{V_{\mathrm{i}}-\sum_{t=1}^{n}\left(C_{\mathrm{f}} N\left(T_{t}-T_{t-1}\right)+1^{\mu} N\right)}{\left(1-Q\left(T_{t}-T_{0}\right)\right)\left(1+r_{T_{t}-T_{0}}\right)^{T_{0}-T_{t}}}
$$

The price difference $\Delta V$ and the implied recovery rate $\mathrm{REC}_{\mathrm{imp}}$ are two major indicators that determine whether a CLN product is overpriced.

\subsubsection{CLNs with a floating coupon rate}

As mentioned in Section 2, CLNs also include products with float-rate coupon payments. Since they only represent a minority of the whole data set, we have not explicitly

\footnotetext{
${ }^{2}$ Price quoted on September 19, 2008 from Onvista.
} 
applied a complex interest rate model for them. Instead, in an analogous way to that used for the practical approaches, we use the forward rates, which are derived from spot rates on the date of issue and are applied to predict the coupon payments. Take a CLN with a quarterly coupon payment of the three-month Euribor rate plus $b$ basis points as an example. In this example, the forward rate for the payment in $T_{t}$ is denoted by $r_{T_{t-1}, T_{t}}$. Adding the $b$ basis points of bonus, the coupon rate for the period $T_{t-1}$ to $T_{t}$ is determined as:

$$
C_{T_{t}}=\left(1+r_{T_{t-1}, T_{t}}\right)^{1 /\left(T_{t}-T_{t-1}\right)}-1+b\left(T_{t}-T_{t-1}\right)
$$

The calculation of the fair price and the implied recovery rate is similar to the case of a CLN with a fixed coupon rate.

\subsubsection{Valuation of a multiple-referenced CLN}

So far, we have been able to value all of the observed CLNs using a single reference entity. The next step is to extend our model to handle multiple referenced CLNs with $m$ reference entities. All of the observed CLNs follow the principle of "first-todefault", which means that as soon as one credit event of any underlying reference entity is identified, the contract will be terminated and paid off immediately. The key issue when pricing a CLN with more than one reference entity is to calculate the probability under which a single reference entity or a group of reference entities will default. Therefore, we extend our model to handle joint defaults.

We choose the single-factor model because it simply assumes that the economic fortune of a creditor depends only on the realization of one latently underlying process, which is interpreted by Merton as the asset value process. ${ }^{3}$ In this model, the default probability $q_{i}$ of the creditor $i$ is the probability under which the latent score variable $R_{i}$ falls below the threshold value $c_{i}$ (Hull (2009, pp. 512-516, 542-547)).

$$
Q_{i}\left(T_{k}\right)=\operatorname{Prob}_{T_{k}}\left(1_{D_{i}}=1\right)=\operatorname{Prob}_{T_{k}}\left(R_{i}<c_{i}\right)
$$

The score variable $R_{i}$ of a portfolio with $m$ creditors can be parameterized by using a single systematic factor, which represents the general uncertainty of the market. The first step is to calculate the joint default probability of two or more different reference entities regarding a time horizon of $T_{k}$, which can be expressed as:

$$
Q_{1,2, \ldots m}\left(T_{k}\right)=\operatorname{Prob}_{T_{k}}\left(1_{D_{1}}=1,1_{D_{2}}=1, \ldots, 1_{D_{m}}=1\right)
$$

This means that a joint default will occur if and only if credit events occur for all creditors in the observed period of time. The joint default probability depends on the

\footnotetext{
${ }^{3}$ Original work on the application of single-factor model for credit risk measurement includes Gordy (2003) and Schönbucher (2007).
} 
joint distribution of $R_{i}$. Since the vector $R=\left(R_{1}, R_{2}, \ldots, R_{m}\right)$ is $m$-dimensional and normally distributed in the correlation matrix $\operatorname{corr}(R)$, all of the marginal distributions are also standard normally distributed. Therefore, the joint default probability can be calculated as follows:

$$
Q_{1,2, \ldots m}\left(T_{k}\right)=\operatorname{Prob}_{T_{k}}\left(R_{1}<c_{1}, R_{2}<c_{2}, \ldots, R_{m}<c_{m}\right)=\Phi_{m}(c, \operatorname{corr}(R))
$$

where $c=\left(c_{1}, c_{2}, \ldots, c_{m}\right)^{\prime}$ is the vector of thresholds and $\Phi_{m}$ is the distribution function of an $m$-dimensional normal distribution with correlation $\operatorname{corr}(R)$. Since $c_{i}$ depends on the individual default probabilities $p_{i}$, the joint default probability can finally be calculated as follows:

$$
\begin{aligned}
& Q_{1,2, \ldots m}\left(T_{k}\right) \\
& \quad=\Phi_{m}\left(\left(\Phi_{1}\left(Q_{1}\left(T_{k}\right)\right)^{-1}, \Phi_{1}\left(Q_{2}\left(T_{k}\right)\right)^{-1}, \ldots, \Phi_{1}\left(Q_{m}\left(T_{k}\right)\right)^{-1}\right)^{\mathrm{T}}, \operatorname{corr}(R)\right)
\end{aligned}
$$

On the basis of the theory of a single-factor Merton model we can calculate the joint default probability of any combination of reference entities within a portfolio given the same time horizon:

$$
\begin{aligned}
Q_{\sigma_{2}(1), \sigma_{2}(2)}\left(T_{k}\right), Q_{\sigma_{3}(1), \sigma_{3}(2), \sigma_{3}(3)}\left(T_{k}\right), \ldots \\
Q_{\sigma_{m-1}(1), \sigma_{m-1}(2), \ldots, \sigma_{m-1}(m-1)}\left(T_{k}\right), Q_{1,2, \ldots m}\left(T_{k}\right)
\end{aligned}
$$

where $\sigma_{j} \in \Re_{j}$ indicates all possible permutations of the original vector $(1,2, \ldots, j)$. The cardinal number of $\Re_{j}$ matches the binomial coefficient:

$$
\left|\Re_{j}\right|=\left(\begin{array}{c}
m \\
j
\end{array}\right)=\left(\begin{array}{c}
m \\
m-j
\end{array}\right)=\frac{m !}{j !(m-j) !}
$$

As the products are first-to-default notes, we are interested in the probability that any of the reference entities will go into default:

$$
\begin{aligned}
& Q_{\text {any }}\left(T_{k}\right) \\
& =\sum_{i=1}^{m} Q_{i}\left(T_{k}\right)-\sum_{\sigma_{2} \in \Re_{2}} Q_{\sigma_{2}(1), \sigma_{2}(2)}\left(T_{k}\right)+\sum_{\sigma_{3} \in \Re_{3}} Q_{\sigma_{3}(1), \sigma_{3}(2), \sigma_{3}(3)}\left(T_{k}\right) \cdots \\
& \quad+(-1)^{m} \sum_{\sigma_{m-1} \in \Re_{m-1}} Q_{\sigma_{m-1}(1), \sigma_{m-1}(2), \ldots, \sigma_{m-1}(m-1)}\left(T_{k}\right)+(-1)^{m+1} Q_{1,2, \ldots, m}
\end{aligned}
$$

For a CLN with $m$ underlying reference entities we first need the $m$ cumulated default probability curves of each individual entity, which can be derived from their CDS 
spreads. The cumulated default probability $Q_{\text {any }}\left(T_{k}\right)$ can be evaluated for each payment day $T_{1}, T_{2}, \ldots, T_{n}$ in the next step. These probabilities can now be used to calculate the fair value in the same way as for the CLN with a single reference entity. So far, we have developed a complete model that is able to value all of the observed CLN products, provided that the data, including CDS spreads and asset correlations, is available.

\section{DATA SOURCES AND TOOLS}

\subsection{CLN data}

As mentioned previously, we identified four major German CLN issuers. ${ }^{4}$ According to our model, the common data that we need to obtain from each individual product description is as follows:

(1) date of issue;

(2) payment dates, including the final payment day;

(3) coupon rate and payment structure;

(4) underlying reference entities.

Apart from the different product names given by the specific issuer, all of these CLN products are constructed similarly. They only differ from each other in the following respects:

(1) number of reference entities (single or multiple);

(2) type of reference entities (corporate or national sovereign);

(3) coupon type (fixed rate, float rate or a mixture of the two);

(4) payment structure (periodic or only at maturity);

(5) issue price and final payment (at, under, or over par).

Altogether, we observe 136 CLN products issued from December 2004 to September 2009. The descriptive statistics are depicted in Table 1 on the next page.

\footnotetext{
${ }^{4}$ We did not directly consider the credit risk of the issuers. Instead we used dummy variables to evaluate possible differences.
} 
ㅇ TABLE 1 Descriptive statistics of observed CLNs.

(a) Issuer, date of issue, maturity and number of references

\begin{tabular}{lccccccc}
\hline Issuer & $\begin{array}{c}\text { Frequency } \\
(\%)\end{array}$ & $\begin{array}{c}\text { Date of } \\
\text { issue }\end{array}$ & $\begin{array}{c}\text { Frequency } \\
(\%)\end{array}$ & Maturity & $\begin{array}{c}\text { Frequency } \\
(\%)\end{array}$ & $\begin{array}{c}\text { No. of } \\
\text { references }\end{array}$ & $\begin{array}{c}\text { Frequency } \\
(\%)\end{array}$ \\
\hline Commerzbank & 26 & 2005 & 9 & $<1$ year & 3 & 1 & 37 \\
DZ Bank & 23 & 2006 & 13 & $1-3$ years & 24 & $2-5$ & 54 \\
HVB & 13 & 2007 & 8 & $>3$ years & 73 & $6-10$ & 5 \\
LBBW & 38 & 2008 & 41 & & & $>10$ & 4 \\
& 2009 & 29 & & & & \\
\hline
\end{tabular}

(b) Coupon type, type of reference, number of payment days and price

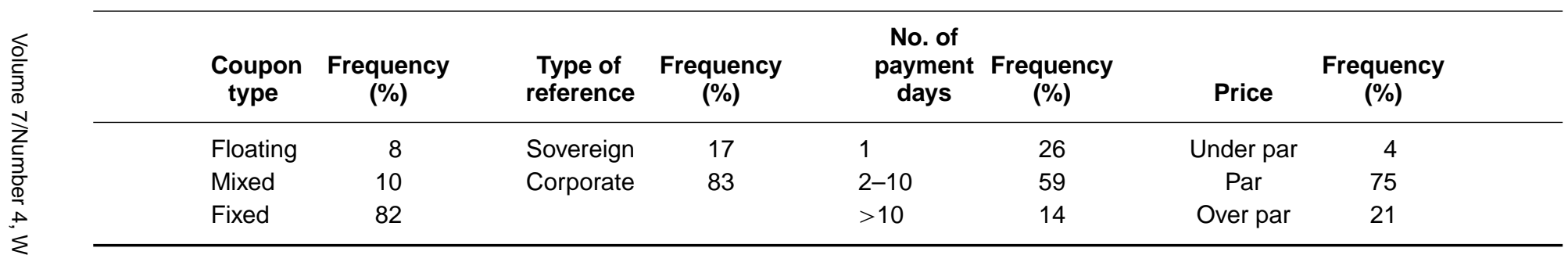




\subsection{Other input parameters}

Besides the CLN data obtained from the individual product descriptions, we also need some other parameters to calculate values in accordance with our model. To discount the cashflows to the date of issue, we need the risk-free spot rate on a daily basis. This yield curve can be estimated by using the Svensson method (Svensson (1994)), which is also used by the German Central Bank. According to the Svensson method, six input parameters are required to calculate the spot rate. For Germany, these parameters are available in the form of time series at the German Central Bank on a daily basis.

The CDS spreads of the reference entities were retrieved through the Thomson Reuters Datastream, which uses the historical data of Credit Market Analysis as a source. ${ }^{5}$ Daily quoted closing rates of senior CDSs with maturities from one to ten years have been available for most of our required reference entities since 2005 .

To calculate the joint default probabilities for CLNs with multiple underlying reference entities, we need their asset correlation. Therefore, for each underlying corporation, we used the stock return of 180 days preceding the date of issue. For national sovereigns, we took the major stock index of each underlying country and calculated the stock return of 180 days (see Table 2 on the next page). In general, Merton's model was applied to sovereigns as required (see Leerbass (1999)). According to that application, the credit risk of a sovereign is closely related to the economic development of a country, which is represented by its stock index. Therefore, the correlation of stock indices may be a good proxy for the correlation of governments' revenues in Merton's model for sovereigns. We note that each of these connections is not deterministic. Nevertheless, we use this methodology only for correlations and not for the implied default probabilities (Scholtens and Hameeteman (2003)).

\section{TESTS AND RESULTS}

\subsection{Overpricing}

The major objective of our work is to find out whether the outstanding CLN products in the German retail market are overpriced. According to our model, this hypothesis can be verified on the basis of either the difference between the calculated fair price $V_{\mathrm{f}}$ and the issue price $V_{\mathrm{i}}$, or the implied recovery rate. To enhance comparability, we choose the price difference $\Delta V$ as a percentage of the issue price. Assuming the recovery rate to be $8.8 \%$, we obtain the results depicted in Figure 6 on page 89 .

As shown in the figure, only 1 out of the 136 CLNs analyzed was issued at the theoretically fair price. All of the others were overpriced, with a maximal difference of $45 \%$. On average, the overpricing reached $8.87 \%$, with a standard deviation of

\footnotetext{
${ }^{5}$ See www.cmavision.com.
} 
TABLE 2 Overview of selected indices as proxies to estimate the default correlation of national sovereigns.

\begin{tabular}{ll}
\hline Country & Index \\
\hline Austria & Austrian Traded Index (ATX) \\
Belgium & Brussels All Share \\
Brazil & Brazil BOVESPA \\
Bulgaria & BSE SOFIX \\
China & Shanghai SE A Share \\
Croatia & Croatian Equity MKT (CROEMI) \\
Colombia & Colombia IGBC Index \\
Denmark & OMX Copenhagen (OMX20) \\
Greece & ATHEX All Share \\
Hungary & Budapest (BUX) \\
India & India BSE (100) National \\
Indonesia & Jakarta SE LQ45 \\
Italy & Milan COMIT General \\
Mexico & Mexico IPC (BOLSA) \\
Poland & Warsaw General Index \\
Portugal & Portugal PSI-20 \\
Romania & Romania BET (L) \\
Russia & Russia RTS Index \\
South Africa & FTSE/JSE All Share \\
Spain & Madrid SE General \\
Sweden & OMX Stockholm 30 (OMXS 30) \\
Switzerland & Swiss Market (SMI) \\
Thailand & Bangkok SET 50 \\
Turkey & ISE National 100 \\
Ukraine & Ukraine KP-DRAGON \\
UK & FTSE All Share \\
Venezuela & Venezuela DS Market \\
\hline &
\end{tabular}

0.082. Following the methodology of Burth et al (2001), a Wilcoxon-signed rank test was applied to verify that result. The probability of symmetrical distribution is less than $0.5 \%$. Therefore, the null hypothesis of symmetrically distributed price differences is refuted. In other words, there exists a significant overpricing. Even if we use a $35 \%$ recovery rate, the result does not change. The average overpricing is still $5.12 \%$. According to the Wilcoxon-signed rank test, the hypothesis of symmetrical distribution can be refuted if the significance level is smaller than $0.5 \%$. Among the sixty-eight most mispriced CLNs, there is only one that is underpriced. Taking that into consideration, the result appears to be even more dramatic if we look at the option 
FIGURE 6 Price difference based on different correlations and recovery rates.

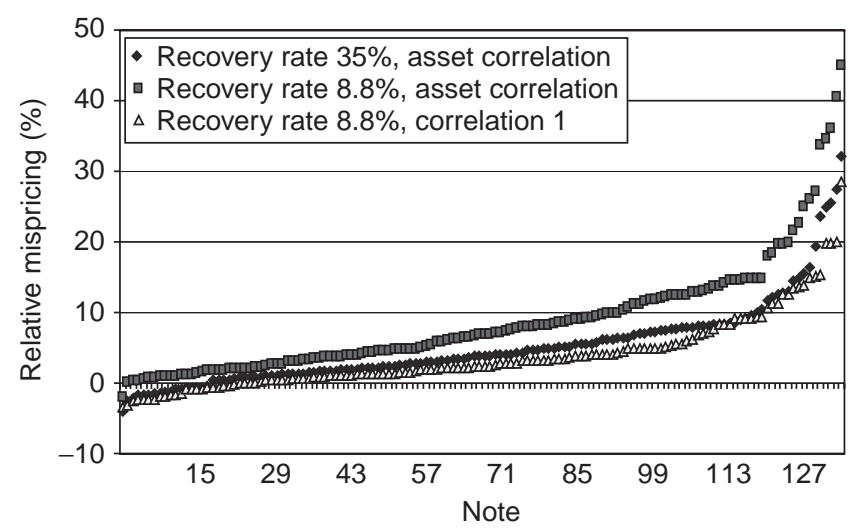

FIGURE 7 Implied recovery rate based on different correlations.

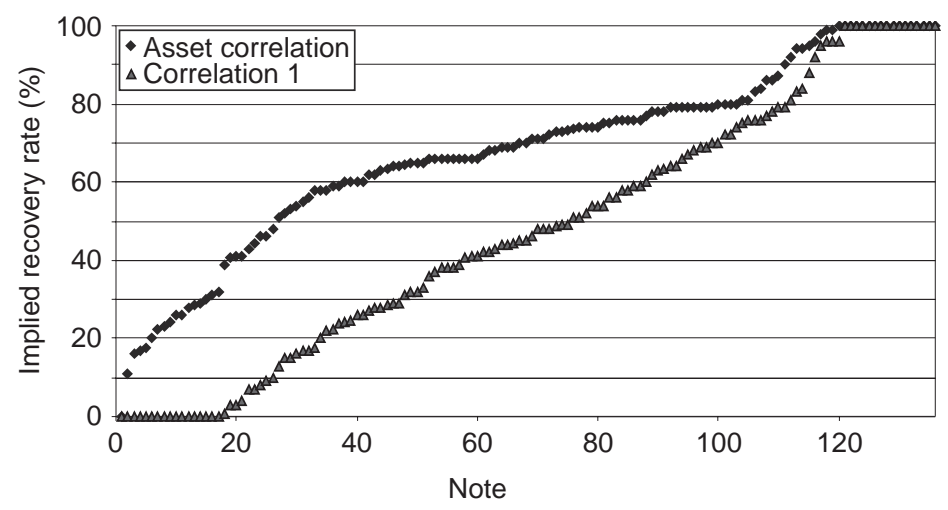

component. In this case, the average overpricing is $67 \%$ and $53 \%$ for the two recovery rates. However, the credit risk of the issuer is neglected in this calculation because it would increase the overpricing.

On the other hand, to make the issue price fair, the implied recovery rates $\mathrm{REC}_{\mathrm{imp}}$ have to be estimated accordingly. The average value of the implied recovery rate is $66 \%$. Seventeen of the 136 CLNs are overpriced even if a recovery rate of $100 \%$ is assumed (see Figure 7). The unrealistic recovery rates further prove that the analyzed CLNs are significantly overpriced. As shown in Figure 8 on the next page, we divide 
FIGURE 8 (a) Average price difference and (b) implied recovery rate grouped by date of issue.
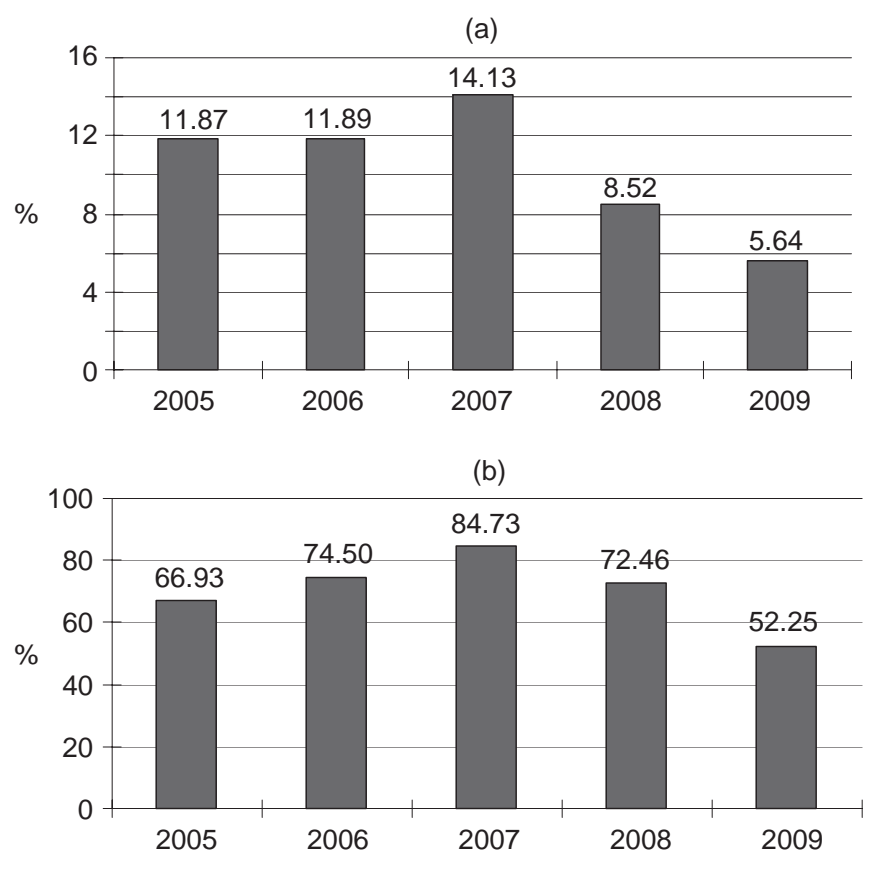

our data by date of issue to find out whether overpricing only exists for a certain period of time. A comparison of the average price differences and the average implied recovery rates of each year indicates that overpricing exists for the entire period of time that we observed, ie, from the beginning of 2005 to the middle of 2009, reaching a peak in 2007.

Finally, we simulate the two extreme cases of totally independent and totally dependent defaults for CLNs with multiple underlying reference entities to test whether the results are robust. In the first case, naturally, all CLNs are overpriced. In the latter case we use the maximum of probabilities of all $m$ entities as the first-to-default probability.

Since, in the case of total dependency, these newly calculated and combined default probabilities are generally lower than the ones calculated on the basis of the Merton model, we will get less significant results of overpricing, which is indicated by smaller positive price differences and lower implied recovery rates.

Compared with the above-mentioned results we have a smaller average price difference of $3.93 \%$, with 121 out of the 136 CLNs being overpriced. The average implied 
recovery rate is lowered to $47.87 \%$ and, assuming a recovery rate of $100 \%$, the same seventeen products are still overpriced. Again, according to the Wilcoxon-signed rank test, there exists a significant overpricing even if we assume the two extreme cases of default correlation.

\subsection{Other hypotheses}

\subsubsection{Operationalization}

To test the other hypotheses regarding possible driving factors that could influence the significance of overpricing, a multiple linear regression analysis is performed. This analysis includes the following influence factors as independent variables (see, for example, Hernández et al (2007b, p. 14)).

Number of reference entities (NoR): used to test hypothesis 2.

Coupon rate (CR): the agreed amount in percentage terms for CLNs with a fixed coupon and estimated average value for CLNs with variable or mixed coupon, used to test hypothesis 3 .

Coupon type (CT): takes either the value 1 for purely fixed coupons or 0 for float-rate based coupons. Used as an additional control variable to test hypothesis 3 .

Maturity (Mat): duration of contracts expressed in years, used to test hypothesis 4 .

Number of payments (NoP): number of agreed payment days assuming no defaults, used to test hypothesis 5 .

Date of issue (DoI): defined as the time since January 1, 2004, used to test hypothesis 5.

Issuer (LBBW, DZ, HVB): three dummy variables for three larger issuers are defined as independent variables to test hypothesis 6 .

Two strong correlations are found by means of these independent variables (see Table 3 on the next page). These correlations can also be explained intuitively as follows:

- the longer the maturity of a CLN contract, the more likely it is that more periodical coupon payments will be agreed upon;

- float-rate CLNs have more payment days since the coupons are mostly paid every three months, while fixed-rate CLNs are mostly paid annually.

Furthermore, since all the HVB products are single referenced, representing the majority of the single-referenced CLNs at the same time, there exist strong correlations between the number of references and the issuer. After regressing each independent variable with all of the others, we found only eight combinations that meet the requirement of not being collinear regressors. These are depicted in Table 4 on page 93 . 
TABLE 3 Correlation matrix of independent variables.

\begin{tabular}{|c|c|c|c|c|c|c|c|c|c|}
\hline & NoR & CR & Dol & Mat & NoP & CT & LBBW & DZ & COBA \\
\hline NoR & 1 & 0.03881 & -0.47495 & 0.18404 & 0.17891 & -0.01228 & -0.07692 & 0.12356 & 0.32509 \\
\hline CR & 0.03881 & 1 & 0.24037 & -0.15025 & 0.16042 & -0.41029 & -0.09749 & -0.22463 & 0.33798 \\
\hline Dol & -0.47495 & 0.24037 & 1 & -0.41845 & -0.20782 & -0.07002 & 0.133486 & -0.21773 & -0.15468 \\
\hline Mat & 0.18404 & -0.15025 & -0.41845 & 1 & 0.81194 & -0.31682 & -0.33951 & 0.06210 & 0.19322 \\
\hline NoP & 0.17891 & 0.16042 & -0.20782 & 0.81194 & 1 & -0.72108 & -0.23509 & -0.16282 & 0.26902 \\
\hline CT & -0.01228 & -0.41029 & -0.07002 & -0.31682 & -0.72108 & 1 & 0.034441 & 0.24697 & -0.16279 \\
\hline LBBW & -0.07692 & -0.09749 & 0.13349 & -0.33951 & -0.23509 & 0.03444 & 1 & -0.41211 & -0.45486 \\
\hline DZ & 0.12356 & -0.22463 & -0.21773 & 0.06210 & -0.16282 & 0.24697 & -0.41211 & 1 & -0.31977 \\
\hline COBA & 0.32509 & 0.33798 & -0.15468 & 0.19322 & 0.26902 & -0.16279 & -0.45486 & -0.31977 & 1 \\
\hline
\end{tabular}


TABLE 4 Combinations with uncorrelated regressors.

\begin{tabular}{llllllll}
\hline 1 & NoR & CR & Dol & CT & LBBW & DZ & \\
2 & NoR & CR & Dol & CT & LBBW & COBA & \\
3 & NoR & CR & Dol & CT & DZ & COBA & \\
4 & NoR & CR & Dol & Mat & CT & DZ & COBA \\
5 & NoR & CR & Mat & CT & DZ & COBA & \\
6 & NoR & CR & Dol & NoP & LBBW & COBA & \\
7 & NoR & CR & Dol & NoP & DZ & COBA & \\
8 & NoR & CR & Dol & NoP & DZ & LBBW & \\
\hline
\end{tabular}

\subsubsection{Regression model: base case}

Since the fourth regression equation is the only one that includes maturity, coupon type and coupon rate, we focus on it:

$$
\Delta V=c_{0}+c_{1} \mathrm{NOR}+c_{2} \mathrm{CR}+c_{3} \mathrm{DoI}+c_{4} \mathrm{Mat}+c_{5} \mathrm{CT}+c_{6} \mathrm{DZ}+c_{7} \mathrm{COBA}+\varepsilon
$$

where $c_{0}$ to $c_{7}$ represent the coefficients to be estimated and $\varepsilon$ is the residual. The result can be summarized, as shown in Table 5 on the next page. Comparing the critical value obtained by means of the $F$-test with the generated test statistics, we can see that the first regression is significant in general, with an adjusted coefficient of determination of 53\%. Four independent variables have a significant impact on the extent of overpricing with a confidence level of $99 \%$, namely, the number of reference entities, the coupon rate, the coupon type and the maturity. Variables with positive coefficients have a positive impact on the extent of overpricing, and vice versa.

However, we found that there exists heteroskedasticity of residuals of several independent variables, which makes the results of $t$-statistics invalid. In the case of the equation above, NoR and CT are affected. To have homoskedastic residuals, we applied a weighted least-squares estimation to the data of affected independent variables (Griffith et al (1993, p. 502)). By applying this transformation to each independent variable with heteroskedastic residuals, we obtain valid $t$-statistics accordingly (indicated by $h(\cdot)$ ). As a result, NoR, CR, Mat and CT remain significant.

\subsection{Robustness checks with different independent variables, different recovery rates and with the recovery rate as a dependent variable}

To check the robustness of these results, the same procedure was applied to the seven other regression equations. The results of those regressions, which are based on the dependent variable $\Delta V$, are shown in part (a) of Table 6 on page 96 . Using the price difference as the dependent variable leads to heteroskedastic residuals for almost half of 
TABLE 5 Regression statistics of the base case.

\begin{tabular}{|c|c|c|}
\hline \multicolumn{3}{|c|}{ (a) Regression statistics } \\
\hline \multicolumn{3}{|c|}{ Multiple correlation coefficient $\quad 0.7494$} \\
\hline \multicolumn{2}{|c|}{ Coefficient of determination } & 0.5615 \\
\hline \multicolumn{2}{|c|}{ Adjusted coefficient of determination } & 0.5376 \\
\hline \multicolumn{2}{|c|}{ Standard error } & 0.0557 \\
\hline \multicolumn{2}{|c|}{ Test statistics $(F)$} & 23.4196 \\
\hline \multicolumn{2}{|c|}{ Observations } & 136 \\
\hline \multicolumn{3}{|c|}{ (b) Coefficient and $t$-statistics } \\
\hline & \multicolumn{2}{|r|}{$\begin{array}{c}t \text {-statistics } \\
p \text {-value }\end{array}$} \\
\hline Intersection & -0.0218 & 0.65 \\
\hline NoR & $0.0393^{* * *}$ & $h(p<0.001)$ \\
\hline $\mathrm{CR}$ & $2.0388 * * *$ & $p<0.001$ \\
\hline Mat & $0.0096 * *$ & 0.0144 \\
\hline CT & $-0.0673^{* * *}$ & $h(p<0.001)$ \\
\hline Dol & -0.0169 & 0.274 \\
\hline $\mathrm{DZ}$ & -0.0192 & 0.1436 \\
\hline COBA & 0.0101 & 0.4542 \\
\hline
\end{tabular}

the independent variables. In accordance with the weighted least-squares regression, NoR, CT, and NoP were tested for significance in all corresponding regressions. ${ }^{6}$ Besides the base case, Mat reaches a significance of $95 \%$ in its robustness check, while the date of issue and the identity of the issuers could not be proved to have a significant impact on the price difference.

As a further robustness check we estimated the above-mentioned regression equations by means of an alternative recovery rate of $35 \%$. The results are depicted in part (b) of Table 6 on page 97. Again, NoR, CR, CT and NoP were tested for significance in all corresponding regressions. This is not the case if we consider the variable Mat. Consequently, NoP seems to be determined by CT rather than by Mat, which can be proven by the fact that $\mathrm{CT}$ of variable notes is extraordinarily high due to the quarterly coupon frequency of the variable notes. Therefore, CT might be the result

\footnotetext{
${ }^{6}$ According to a Kolmogorov-Smirnov test and a likelihood-ratio test, the hypothesis of nonnormal residuals cannot be rejected in all but two regressions on a 5\% level. After correcting for the heteroskedasticity the effect of nonnormality vanishes. Due to the application of DoI in seven of the eight regressions as independent variables, positive or negative autocorrelation in the residuals cannot be verified.
} 
of the use of the common bank approach in valuing floaters. Hence, it is unlikely that credit risk-free floaters that are are priced correctly.

In our last robustness check we repeated the above-mentioned regressions using the recovery rate as the new dependent variable. In contrast with the earlier regressions, only a few equations showed heteroskedasticity, and only a few required transformation. All residuals proved to be distributed normally. Furthermore, we obtain a lower adjusted coefficient of determination compared with the first regression. The results of all regressions based on the dependent variable $\mathrm{REC}_{\mathrm{imp}}$ are shown in Table 7 on page 98. Compared with the results based on price differences, the new regressions suggest that the regressors NoR, CT and Mat are significant. While the significance of NoP and CR could only be verified partially, the impact of issuer and date of issue still cannot be proved robustly.

\subsection{Discussion of the results}

Consolidating the base case as well as the robustness checks, we conclude that the first three hypotheses are valid for the analyzed data, while the other three hypotheses cannot be verified statistically.

It is difficult, especially for retail investors, to estimate the default risks of large numbers of underlying reference entities, since the calculation requires sophisticated models and a wide range of data. This asymmetry of information often encourages issuers to overprice their products. That complexity, measured here by the number of reference entities, plays a key role and is supported by our results and by the extent of overpricing, which is in line with many studies (see, for example, Gruenbichler and Wohlwend (2005, p. 372), Hernández et al (2007b, p. 26), Szymanowska et al (2009, p. 907) and Stoimenov and Wilkens (2005, p. 2986)).

Moreover, a complex coupon structure and long maturity that involve both fixed and floating coupon rates might seem to be more attractive for most investors (for similar results, see Benet et al (2006, p. 124) and Hernández et al (2007a, p. 33)) since they often assess the conditions at the time of first sight. Hidden factors regarding highly fixed coupon rates usually make these products even more overpriced compared with those with a simple coupon structure. This is slightly inconsistent with studies by Burth et al (2001, p. 13) and Hernández et al (2007b, p. 26), whose samples include non-coupon-bearing instruments, but our results are consistent with those of Wallmeier and Diethelm (2009, p. 17).

On the other hand, no significant impact on the extent of overpricing can be proved for the factor date of issue and no significant difference is found with respect to the pricing behavior of different issuers (see Hernández et al (2007a, p. 32) and Szymanowska et al (2009, p. 916) for contrasting results) either. In this regard our results are consistent with Wallmeier and Diethelm (2009). 
TABLE 6 Consolidated results of regressions based on price difference. [Table continues on next page.]

(a) Recovery rate $8.8 \%$ and asset correlation

\begin{tabular}{|c|c|c|c|c|c|c|c|c|c|c|}
\hline $\begin{array}{c}\text { Sig. } \\
\text { in } \\
\text { reg. }\end{array}$ & $\begin{array}{c}\text { Adj. } \\
R^{2} \\
(\%)\end{array}$ & NoR & CR & CT & Dol & Mat & NoP & LBBW & DZ & COBA \\
\hline 1 & 53.4 & $\begin{array}{c}0.0404 \\
h(p<0.001)^{* * *}\end{array}$ & $\begin{array}{c}1.6316 \\
h(p<0.001)^{* * *} h\end{array}$ & $\begin{array}{c}-0.0750 \\
h(p<0.001)^{* * *}\end{array}$ & $\begin{array}{l}-0.0136 \\
h(0.4063)\end{array}$ & - & - & $\begin{array}{l}-0.0289 \\
h(0.0079)^{* * *}\end{array}$ & $\begin{array}{l}-0.0359 \\
(0.0094)^{* * *}\end{array}$ & - \\
\hline 2 & 51.6 & $\begin{array}{c}0.0398 \\
h(p<0.001)^{* * *}\end{array}$ & $\begin{array}{c}1.6766 \\
h(p<0.001)^{* * *}\end{array}$ & $\begin{array}{l}-0.0775 \\
(p<0.001)^{* * *}\end{array}$ & $\begin{array}{l}-0.0266 \\
(0.0713)^{*}\end{array}$ & - & - & $\begin{array}{c}-0.0069 \\
(0.5528)\end{array}$ & - & $\begin{array}{c}0.0194 \\
(0.1690)\end{array}$ \\
\hline 3 & 51.9 & $\begin{array}{c}0.0385 \\
h(p<0.001)^{* * *}\end{array}$ & $\begin{array}{c}1.6808 \\
h(p<0.001)^{* * *}\end{array}$ & $\begin{array}{l}-0.0743 \\
(p<0.001)^{* * *}\end{array}$ & $\begin{array}{l}-0.0392 \\
h(0.0305)^{* *}\end{array}$ & - & - & - & $\begin{array}{c}-0.0148 \\
(0.2646)\end{array}$ & $\begin{array}{c}0.0179 \\
(0.1836)\end{array}$ \\
\hline 4 & 53.8 & $\begin{array}{c}0.0393 \\
h(p<0.001)^{* * *}\end{array}$ & $\begin{array}{l}2.0388 \\
(p<0.001)^{* * *} h\end{array}$ & $\begin{array}{c}-0.0673 \\
h(p<0.001)^{* * *}\end{array}$ & $\begin{array}{c}-0.0169 \\
(0.2740)\end{array}$ & $\begin{array}{l}0.0096 \\
(0.0144)^{* *}\end{array}$ & - & - & $\begin{array}{c}-0.0192 \\
(0.1436)\end{array}$ & $\begin{array}{c}0.0101 \\
(0.4542)\end{array}$ \\
\hline 5 & 53.7 & $\begin{array}{c}0.0412 \\
h(p<0.001)^{* * *}\end{array}$ & $\begin{array}{c}1.8728 \\
h(p<0.001)^{* * *}\end{array}$ & $\begin{array}{l}-0.054 \\
(p<0.001)^{* * *}\end{array}$ & - & $\begin{array}{c}0.0094 \\
h(0.0067)^{* * *}\end{array}$ & - & - & $\begin{array}{c}-0.0176 \\
(0.1781)\end{array}$ & $\begin{array}{c}0.0111 \\
(0.4095)\end{array}$ \\
\hline 6 & 52.7 & $\begin{array}{c}0.0374 \\
h(p<0.001)^{* * *}\end{array}$ & $\begin{array}{c}2.2184 \\
h(p<0.001)^{* * *}\end{array}$ & - & $\begin{array}{r}-0.0145 \\
(0.3231)\end{array}$ & - & $\begin{array}{c}0.0325 \\
h(p<0.001)^{* * *}\end{array}$ & $\begin{array}{c}0.0027 \\
(0.8123)\end{array}$ & - & $\begin{array}{c}0.0141 \\
(0.3143)\end{array}$ \\
\hline 7 & 53.4 & $\begin{array}{c}0.0379 \\
h(p<0.001)^{* * *}\end{array}$ & $\begin{array}{c}2.2012 \\
h(p<0.001)^{* * *}\end{array}$ & - & $\begin{array}{c}-0.0181 \\
(0.2233)\end{array}$ & - & $\begin{array}{c}0.0318 \\
h(p<0.001)^{* * *}\end{array}$ & - & $\begin{array}{c}-0.0177 \\
(0.1724)\end{array}$ & $\begin{array}{l}0.0066 \\
(0.6170)\end{array}$ \\
\hline 8 & 53.8 & $\begin{array}{c}0.0377 \\
h(p<0.001)^{* * *}\end{array}$ & $\begin{array}{c}2.1727 \\
h(p<0.001)^{* * *}\end{array}$ & - & $\begin{array}{c}-0.0183 \\
(0.2117)\end{array}$ & - & $\begin{array}{c}0.0305 \\
h(p<0.001)^{* * *}\end{array}$ & $\begin{array}{c}-0.0140 \\
(0.2380)\end{array}$ & $\begin{array}{l}-0.0304 \\
h(0.0165)^{* *}\end{array}$ & - \\
\hline
\end{tabular}


TABLE 6 Continued.

(b) Recovery rate $35 \%$ and asset correlation

\begin{tabular}{|c|c|c|c|c|c|c|c|c|c|c|}
\hline $\begin{array}{l}\text { Sig. } \\
\text { in } \\
\text { reg. }\end{array}$ & $\begin{array}{l}\text { Adj. } \\
R^{2} \\
(\%)\end{array}$ & NoR & CR & CT & Dol & Mat & NoP & LBBW & DZ & COBA \\
\hline 1 & 52.7 & $\begin{array}{c}0.0295 \\
h(p<0.001)^{* * *}\end{array}$ & $\begin{array}{c}0.8804 \\
h(0.0126)^{* *}\end{array}$ & $\begin{array}{l}-0.0622 \\
(p<0.001)^{* * *}\end{array}$ & $\begin{array}{c}-0.0127 \\
(0.2305)\end{array}$ & - & - & $\begin{array}{l}-0.0222 \\
h(0.0052)^{* * *}\end{array}$ & $\begin{array}{l}-0.0228 \\
h(0.0113)^{* *}\end{array}$ & - \\
\hline 2 & 51.2 & $\begin{array}{c}0.0299 \\
h(p<0.001)^{* * *}\end{array}$ & $\begin{array}{c}0.9275 \\
h(0.0111)^{* *}\end{array}$ & $\begin{array}{l}-0.0666 \\
(p<0.001)^{* * *}\end{array}$ & $\begin{array}{r}-0.0107 \\
(0.3205)\end{array}$ & - & - & $\begin{array}{c}-0.0090 \\
(0.2879)\end{array}$ & - & $\begin{array}{l}0.0098 \\
(0.3434)\end{array}$ \\
\hline 3 & 50.9 & $\begin{array}{c}0.0287 \\
h(p<0.001)^{* * *}\end{array}$ & $\begin{array}{c}0.9274 \\
h(0.0113)^{* *}\end{array}$ & $\begin{array}{l}-0.0649 \\
(p<0.001)^{* * *}\end{array}$ & $\begin{array}{c}-0.0134 \\
(0.2183)\end{array}$ & - & - & - & $\begin{array}{c}-0.0071 \\
(0.4651)\end{array}$ & $\begin{array}{c}0.0121 \\
(0.2199)\end{array}$ \\
\hline 4 & 51.3 & $\begin{array}{c}0.0288 \\
h(p<0.001)^{* * *}\end{array}$ & $\begin{array}{l}1.1521 \\
(0.0016)^{* * *}\end{array}$ & $\begin{array}{c}-0.0604 \\
h(p<0.001)^{* * *}\end{array}$ & $\begin{array}{r}-0.0075 \\
(0.5142)\end{array}$ & $\begin{array}{c}0.0041 \\
(0.1548)\end{array}$ & - & - & $\begin{array}{r}-0.0090 \\
(0.3569)\end{array}$ & $\begin{array}{c}0.0088 \\
(0.3848)\end{array}$ \\
\hline 5 & 51.5 & $\begin{array}{c}0.0300 \\
h(p<0.001)^{* * *}\end{array}$ & $\begin{array}{c}1.0153 \\
h(0.0059)^{* * *}\end{array}$ & $\begin{array}{l}-0.0561 \\
(p<0.001)^{* * *}\end{array}$ & - & $\begin{array}{l}0.0048 \\
(0.0770)^{*}\end{array}$ & - & - & $\begin{array}{c}-0.0083 \\
(0.3928)\end{array}$ & $\begin{array}{c}0.0092 \\
(0.3928)\end{array}$ \\
\hline 6 & 47.3 & $\begin{array}{c}0.0274 \\
h(p<0.001)^{* * *}\end{array}$ & $\begin{array}{c}1.5003 \\
h(p<0.001)^{* * *}\end{array}$ & - & $\begin{array}{c}-0.0026 \\
(0.8211)\end{array}$ & - & $\begin{array}{c}0.0221 \\
h(p<0.001)^{* * *}\end{array}$ & $\begin{array}{c}-0.0020 \\
(0.8246)\end{array}$ & - & $\begin{array}{c}0.0064 \\
(0.5538)\end{array}$ \\
\hline 7 & 47.8 & $\begin{array}{c}0.0278 \\
h(p<0.001)^{* * *}\end{array}$ & $\begin{array}{c}1.4836 \\
h(p<0.001)^{* * *}\end{array}$ & - & $\begin{array}{c}-0.0052 \\
(0.6486)\end{array}$ & - & $\begin{array}{c}0.0219 \\
(p<0.001)^{* * *}\end{array}$ & - & $\begin{array}{c}-0.0111 \\
(0.2650)\end{array}$ & $\begin{array}{c}0.0036 \\
(0.7247)\end{array}$ \\
\hline 8 & 48.5 & $\begin{array}{c}0.0271 \\
h(p<0.001)^{* * *}\end{array}$ & $\begin{array}{c}1.4429 \\
h(p<0.001)^{* * *}\end{array}$ & - & $\begin{array}{c}-0.0051 \\
(0.6525)\end{array}$ & - & $\begin{array}{c}0.0207 \\
h(p<0.001)^{* * *}\end{array}$ & $\begin{array}{c}-0.0124 \\
(0.1741)\end{array}$ & $\begin{array}{l}-0.0195 \\
(0.0707)^{*}\end{array}$ & - \\
\hline
\end{tabular}


TABLE 7 Consolidated results of regressions based on implied recovery rate.

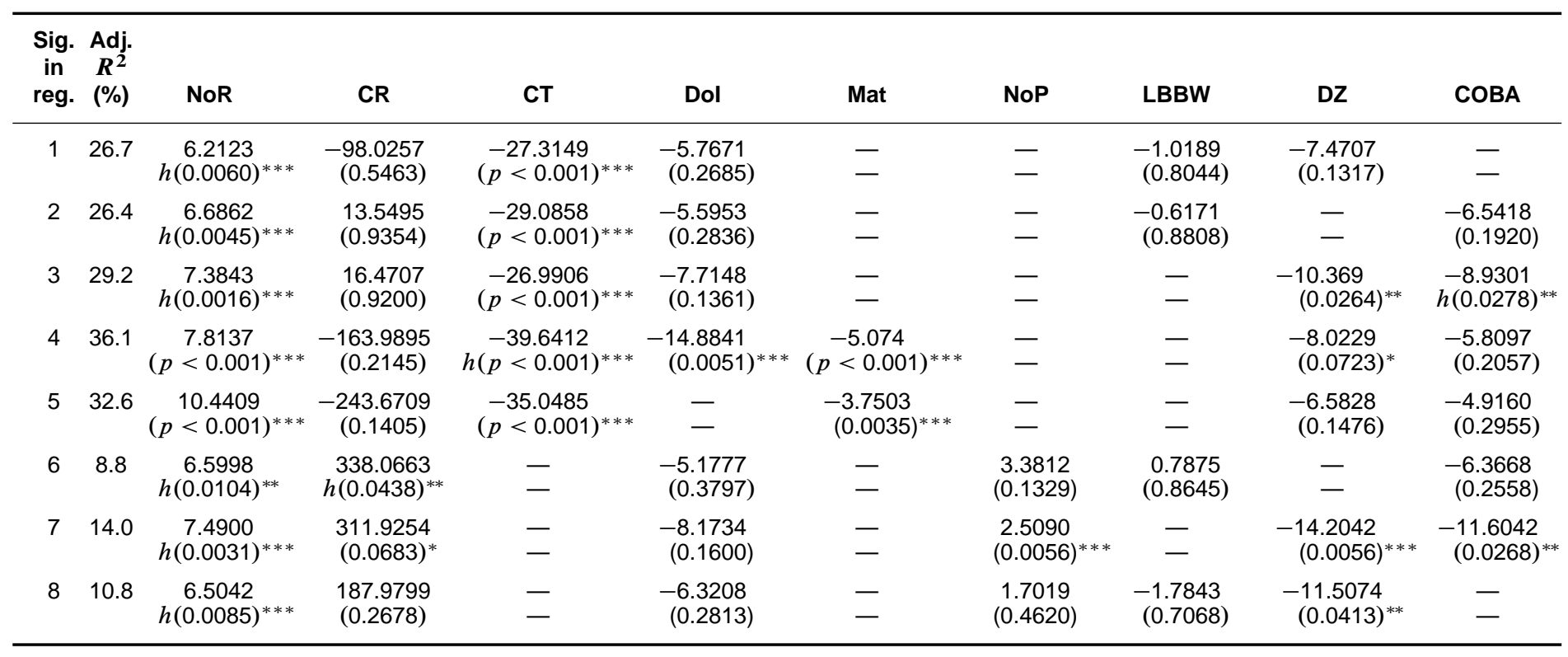

Column 2 shows the adjusted $R^{2}$ of the original regression. Columns 3-11 show the estimated coefficient, with $p$-values in parentheses. $h$ indicates a new estimation after

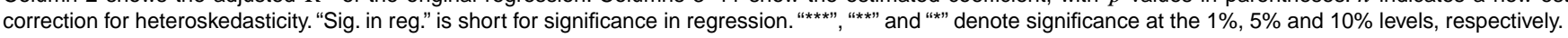




\section{CONCLUSION AND OUTLOOK}

In this paper we analyzed the pricing of the 136 outstanding CLNs of the four major issuers in the German market. For this purpose we applied a market-based valuation model for CLNs based on the reduced model by Jarrow and Turnbull, which we extended using the single-factor Merton model to estimate the joint default probabilities by means of asset correlations. The model was calibrated using CDS spreads and correlations of stock returns for the underlying reference entities.

We discovered that the observed CLNs are generally greatly overpriced in the primary market. The result is, therefore, robust to changes in recovery rates or correlation coefficients. Furthermore, four of the six hypotheses that we had previously formulated were supported by our tests. For CLNs in the German market, we analyzed the issue price for the first time, and our major finding is widely consistent with previous results in the literature. Since they are market makers, issuers of structured financial products participate in almost every transaction and, therefore, they have the incentive to overprice. Furthermore, the more complex the product and the less transparent the market, the more overpricing there tends to be. This consideration is confirmed by the results regarding our major hypothesis of overpricing, and the extent of overpricing is positively correlated with the number of underlying reference entities, the coupon rates and the time to maturity of the contract.

There are a lot of possibilities for extensions to this work. In addition to the valuation of CLNs on the date of their issue, we could apply the same model to calculate the daily fair prices and compare them with the daily quoted prices. By tracking the daily development of price differences, the hypothesis of the product life cycle can also be tested for CLNs. Moreover, the change of interest rates can also be modeled more specifically to calculate fair prices for CLNs with float coupon payments more accurately. Last, but not least, the valuation framework can be used for CLN products issued in other regions to test whether the hypotheses verified for the German market are universally valid.

\section{REFERENCES}

Benet, B., Giannetti, A., and Pissaris, S. (2006). Gains from structured product markets: the case of reverse-exchangeable securities (RES). Journal of Banking and Finance 30(1), 111-132.

Bielecki, T., and Rutkowski, M. (2002). Credit Risk: Modeling, Valuation and Hedging. Springer.

Brown, C., and Davis, K. (2004). Dividend protection at a price: lessons from endowment warrants. Journal of Derivatives 12(4), 62-68.

Burth, S., Kraus, T., and Wohlwend, H. (2001). The pricing of structured products in the Swiss market. Working Paper, Swiss Institute of Banking and Finance, University of St. Gallen, St. Gallen. 
Chen, A., Kensinger, J., and Pu, H. (1990). An analysis of PERCS. Journal of Financial Engineering 3(6), 85-108.

Chen, K. C., and Sears, S. (1990). Pricing the spin. Financial Management 19(2), 36-47.

Duffie, D., and Singleton, K. (1999). Econometric modeling of term structures of defaultable bonds. Review of Financial Studies 12(4), 687-720.

Entrop, O., Scholz, H., and Wilkens, M. (2009). The price-setting behavior of banks: an analysis of open-end leverage certificates on the German market. Journal of Banking and Finance 33(5), 874-882.

Fabozzi, F., Davis, H., and Choudhry, M. (2007). Credit-linked notes: a product primer. Journal of Structured Finance 12(4), 67-77.

Gordy, M. (2003). A risk-factor model foundation for ratings-based bank capital rules. Journal of Financial Intermediation 12(3), 199-232.

Griffith, W., Hill, C., and Judge, G. (1993). Learning and Practicing Econometrics. John Wiley \& Sons, New York.

Gruenbichler, A., and Wohlwend, H. (2005). The valuation of structured products: empirical findings for the Swiss market. Financial Markets and Portfolio Management 19(4), 361380.

Hernández, R., Lee, W., and Liu, P. (2007a). An economic analysis of reverse exchangeable securities: an option-pricing approach. Working Paper, Sam M. Walton College of Business, University of Arkansas, Fayetteville.

Hernández, R., Lee, W., and Liu, P. (2007b). An economic analysis of the Japanese reverse exchangeable market. Working Paper, Sam M. Walton College of Business, University of Arkansas, Fayetteville.

Hui, C.-H., and Lo, C.-F. (2002). Effect of asset value correlation on credit-linked note values. International Journal of Theoretical and Applied Finance 5(5), 455-478.

Hull, J. (2009). Options, Futures and Other Derivatives, 7th edn. Pearson, Upper Saddle River, NJ.

Hull, J., and White, A. (2003). The valuation of credit default swaptions. Journal of Derivatives 10(3), 40-50.

International Swaps and Derivatives Association (2003). Standard North American corporate CDS contract specification. ISDA, New York.

International Swaps and Derivatives Association (2009). Standard North American corporate CDS converter specification. ISDA, New York.

Jarrow, R., and Turnbull, S. (1997). A Markov model for the term structure of credit risk spreads. Review of Financial Studies 10, 481-523.

Leerbass, F. B. (1999). A simple approach to country risk. Working Paper, University of Dresden.

Merrick Jr., J. (2001). Crisis dynamics of implied default recovery ratios. Journal of Banking and Finance 25(10), 1921-1939.

Merton, R. C. (1974). On the pricing of corporate debt: the risk structure of interest rates. Journal of Finance 29(2), 449-470.

Press, W., Teukolsky, S., Vetterling, W., and Flannery, B. (2007). Numerical Recipes: The Art of Scientific Computation, 3rd edn. Cambridge University Press.

Scholtens, B., and Hameeteman, D. (2003). Joint default probabilties and country risk. Working Paper, University Groningen. 
Schönbucher, P. (2007). Credit Derivatives Pricing Models. John Wiley \& Sons, New York. Stoimenov, P., and Wilkens, S. (2005). Are structured products "fairly" priced? An analysis of the German market for equity-linked instruments. Journal of Banking and Finance 29(12), 2971-2993.

Svensson, L. (1994). Estimating and interpreting forward interest rates: Sweden 19921994. IMF Working Paper 94/114, New York.

Szymanowska, M., Horst, J. T., and Veld, C. (2009). Reverse convertible bonds analyzed. Journal of Futures Markets 29(10), 895-919.

Telpner, J. (2004). A survey of structured notes. Journal of Structured and Project Finance 9(4), 6-19.

Wallmeier, M., and Diethelm, M. (2009). Market pricing of exotic structured products: the case of multi-asset barrier reverse convertibles in Switzerland. Journal of Derivatives 17(2), 59-72.

Wilkens, S., Erner, C., and Roeder, K. (2003). The pricing of structured products in Germany. Journal of Derivatives 11(4), 55-69. 
